\title{
Indoor Air Quality Assessment at the Library of the National Observatory of Athens, Greece
}

\author{
Fani Drougka ${ }^{1}$, Eleni Liakakou ${ }^{2 *}$, Arezina Sakka ${ }^{1}$, Dimitrios Mitsos ${ }^{1}$, Nikolaos Zacharias ${ }^{1}$, \\ Nikolaos Mihalopoulos ${ }^{2,3}$, Evangelos Gerasopoulos ${ }^{2}$ \\ ${ }^{1}$ University of the Peloponnese, Department of History, Archaeology \& Cultural Resources Management, 24100 \\ Kalamata, Greece \\ ${ }^{2}$ National Observatory of Athens, Institute for Environmental Research and Sustainable Development, 15236 Athens, \\ Greece \\ ${ }^{3}$ Environmental Chemical Processes Laboratory (ECPL), Department of Chemistry, University of Crete, 71003 Crete, \\ Greece
}

\begin{abstract}
Indoor environmental factors, such as microclimatic conditions (viz., the temperature and relative humidity) and pollutant concentrations, crucially affect the exhibits and artworks in a museum. To evaluate the air quality inside the library hosted by the Museum of Geoastrophysics of the National Observatory of Athens, a monitoring campaign was performed during summertime (August 2016). The findings were compared against scientifically accepted standards and recommended conditions for repositories and paperwork exhibition areas. The temperature and the relative humidity proved to be the most critical threats to the book collection, with the measured temperatures exceeding the recommended limits. Both parameters also displayed diurnal fluctuations, which are not recommended. Synergistically, these uncontrolled conditions contribute to book deterioration on a long-term basis, resulting in color and mechanical damage to the fibers and the growth of mold. Furthermore, despite only moderate infiltration, the library exhibited unacceptably high levels of pollutants, such as $\mathrm{SO}_{2}$, $\mathrm{NO}_{2}$ and $\mathrm{O}_{3}$, which also cause the embrittlement and discoloration of paper as well as a weakening or powdering of leather book covers.
\end{abstract}

Keywords: Microclimatic conditions; Air pollution; Indoor air quality; Books; Organic materials.

\section{INTRODUCTION}

It is well known that human activity has contributed to progressive deterioration of environmental conditions. Excessive air pollution in many cities especially those linked with aerosols (e.g., black carbon), acidic compounds (e.g., sulfur dioxide $\left[\mathrm{SO}_{2}\right]$, nitrogen oxides $\left.\left[\mathrm{NO}_{x}\right], \mathrm{HNO}_{3}\right)$ and oxidants (e.g., ozone $\left[\mathrm{O}_{3}\right], \mathrm{H}_{2} \mathrm{O}_{2}$ ) affected historic and modern materials and significant damages have been observed in historical and cultural structures and monuments. Climate change accelerates the degradation due to increased temperature $(\mathrm{T})$ or other extreme events such as flooding. The outdoor atmospheric conditions can also affect the indoor ones and consequently impact on degradation of collections exposed in museums. Indeed, indoor air quality (IAQ) at museums and historical buildings is considered in general as

\footnotetext{
${ }^{*}$ Corresponding author.

Tel.: +30-210-810-9139; Fax: +30-210-810-3236

E-mail address: liakakou@noa.gr
}

major issue of concern for cultural heritage preservation (Ankersmit and Stappers, 2016). The exposure of artworks and materials to inappropriate temperature and relative humidity (RH) levels, as well as to gaseous and particulate pollutants emitted from either indoor or outdoor sources contributes to their decay. Under low air pollution conditions, direct effects on materials are rather limited, while in the case of long-term exposure to a heavily polluted environment, more serious effects, such as surface alteration, color change or even weakening of the material may occur (Brown et al., 2002; Andreopoulou-Magkou and Mariolopoulos, 2005; Zorpas and Skouroupatis, 2016). Simultaneously, the impact of the touristic activities on indoor cultural heritage areas should not be neglected (Worobiec et al., 2008). The indooroutdoor interactions in general impact on the air quality of the storage or exposition areas. In this context, monitoring and controlling the indoor microclimatic conditions and the level of pollutants is of major significance and is priority for the conservation and preservation strategies implemented during exhibitions or materials storage.

Temperature and relative humidity are the most crucial risk factors for libraries and archival collections as they are 
potential catalysts of aging processes and their increase to extremely high levels favors the growth of insects (Adcock, 1998; Henderson, 2013; Sarantakos, 2013), especially in leather (Vujcic et al., 2017). An increase in T by $10^{\circ} \mathrm{C}$, or even by $5^{\circ} \mathrm{C}$ for unstable materials could accelerate the chemical decay reactions' rate even by a factor of 2 (Henderson, 2013). In general terms discoloration, fading and blackening could occur due to high temperatures. Hydroscopic archival collections (organic materials such as paper, leather and parchment) can readily absorb moisture from the environment resulting in the expansion of the material. Furthermore, according to Sterflinger (2010), high RH levels (above 55\%) favor the development of mold and additional biological damages by microorganisms. In contrast, when the levels of relative humidity decrease, organic materials lose moisture content and tend to shrink. The previously described expansion and contraction of hydroscopic materials due to fluctuations of temperature and relative humidity can also lead to mechanical damage of the objects.

The presence of air pollutants in exhibition areas or storage rooms and under uncontrolled micro-environmental conditions could further determine the fate of book collections, mainly due to acidic hydrolysis processes (Daniel et al., 1990; Daniels, 1996; De Feber et al., 1998; Pavlogeorgatos, 2003; Tétreault, 2003). Paper and leather are among the materials seriously affected due to their sensitivity to acidic compounds. By considering the endogenous decay factors of vulnerable materials, such as the cellulose macromolecular or production properties of the paper (Dirksen, 1997; Adcock, 1998; Andreopoulou-Magkou and Mariolopoulos, 2005; Area and Cheradame, 2011; Kliafa, 2013), the long-term exposure to risk conditions are of great importance for such artworks or exhibits. Blades et al. (2000) mention that $\mathrm{SO}_{2}$ can cause embrittlement and discoloration of the paper and a weakening or powdered surface of the leather covers of books known as "red rot" when in combination with a presence of high RH and oxygen levels (Dirksen, 1997; AndreopoulouMagkou and Mariolopoulos, 2005; Kite and Thomson, 2006). Specifically, $\mathrm{SO}_{2}$ can be absorbed onto cellulosic materials, such as paper, where it catalytically hydrolyzes to $\mathrm{H}_{2} \mathrm{SO}_{4} \cdot \mathrm{H}_{2} \mathrm{SO}_{3}$ and $\mathrm{H}_{2} \mathrm{SO}_{4}$ (ASHRAE, 2015). Moreover, $\mathrm{SO}_{2}$ could react with leather, breaking down its molecular structure and weakening the material. As a result, it contributes to producing a powdery surface, which is easily abraded. Ozone, as a strong oxidant, causes fading of dyes and pigments and induces attack on organic materials (Morten, 2006). $\mathrm{NO}_{x}$ and $\mathrm{O}_{3}$ in humid environments enhance the $\mathrm{SO}_{2}$ uptake (Johansson and Lennholm, 2000; Johansson et al., 2000), catalyzing thus the hydrolysis reactions. Additionally, acidic or alkaline particulate matter (PM) favors the discoloration processes through deposition (Grau-Bové et al., 2016).

The current study, undertaken during August 2016, focuses on the IAQ at the library of the Museum of Geoastrophysics (www.noa.gr/museum) of the National Observatory of Athens (NOA). The museum is situated close to the center of Athens; therefore, the area is influenced by typical urban pollutants. Apart from local urban emissions (e.g., traffic), the Attica Basin is subjected to long-range transport and accepts burdens of contaminants of different origin (e.g., Gerasopoulos et al.,
2009; Paraskevopoulou et al., 2015; Athanasopoulou et al., 2017; Fourtziou et al., 2017; Gratsea et al., 2017). Furthermore, the occurrence of heat waves (Founda and Giannakopoulos, 2009; Founda, 2011) should be taken into consideration, due to their synergy with indoor heating/cooling practices and interaction with emission sources and pollutants' fate in the atmosphere as well. Despite the possible effects of the ambient conditions on the indoor environment, neither measurements nor installation of permanent monitoring equipment had been considered up to now for the library.

Our work aims to monitor and evaluate, for the first time, the temperature, relative humidity and air pollutant levels in the library room, to enable understanding of indoor-outdoor interactions with respect to natural and artificial ventilation of the building, and finally, to assist the museum authorities in undertaking tailored measures for the preservation of the exhibits. Also, in an effort to assess the risk related to the impact of IAQ on the library's book collection, we compared our findings with already published reference or limit values and other available tools for evaluation of the micro-environmental conditions impact on cultural heritage $(\mathrm{CH})$ artifacts

\section{METHODS}

\section{Description of the Museum Location and the Library}

The Attica Basin, which includes Athens, is the most urbanized area in Greece, with $35 \%$ of the population of the country residing in the area using $52 \%$ of the private vehicles in the country (ELSTAT Annual Report 2014) therefore, resulting in increased local emissions. The Museum of Geoastrophysics of NOA is situated in the historical center of the city of Athens at the top of the Hill of the Nymphs, in close vicinity to the hill of the Acropolis (Fig. 1) and a relatively short distance $(0.5-2 \mathrm{~km})$ from the traffic-congested streets of the commercial center of Athens. The museum building is more than 170 years old, made of stone and hosts the library on the ground floor, where rare books, journals and other important manuscripts, even from the $16^{\text {th }}$ century, are kept. The library is isolated from the rest of the museum and 1-3 staff members, including maintenance personnel, work in the room occasionally, but not simultaneously. There are no materials covering the floor of the room, the top portion of the walls that are close to the ceiling is decorated with paintings and on the roof there is a metallic remnant of an old opening mechanism used for sky observations. Closed windows, no lighting and occasionally operated airconditioning system (for cooling or heating during meetings or guided tours) are the regular maintenance conditions. The windows are rarely opened for short periods, during working hours, to provide ventilation.

The building has been renovated since its inception in 1842 up to 2008 , when it was converted into a museum, without interventions in the construction materials (stones). Despite the building renovation (e.g., roof restoration in 2008 and new shutters and wall painting in 2014), the books are kept under uncontrolled thermo-hydrometric conditions, without heating, ventilation, and air-conditioning (HVAC) system. Dust is deposited on the books, whereas fragility, 

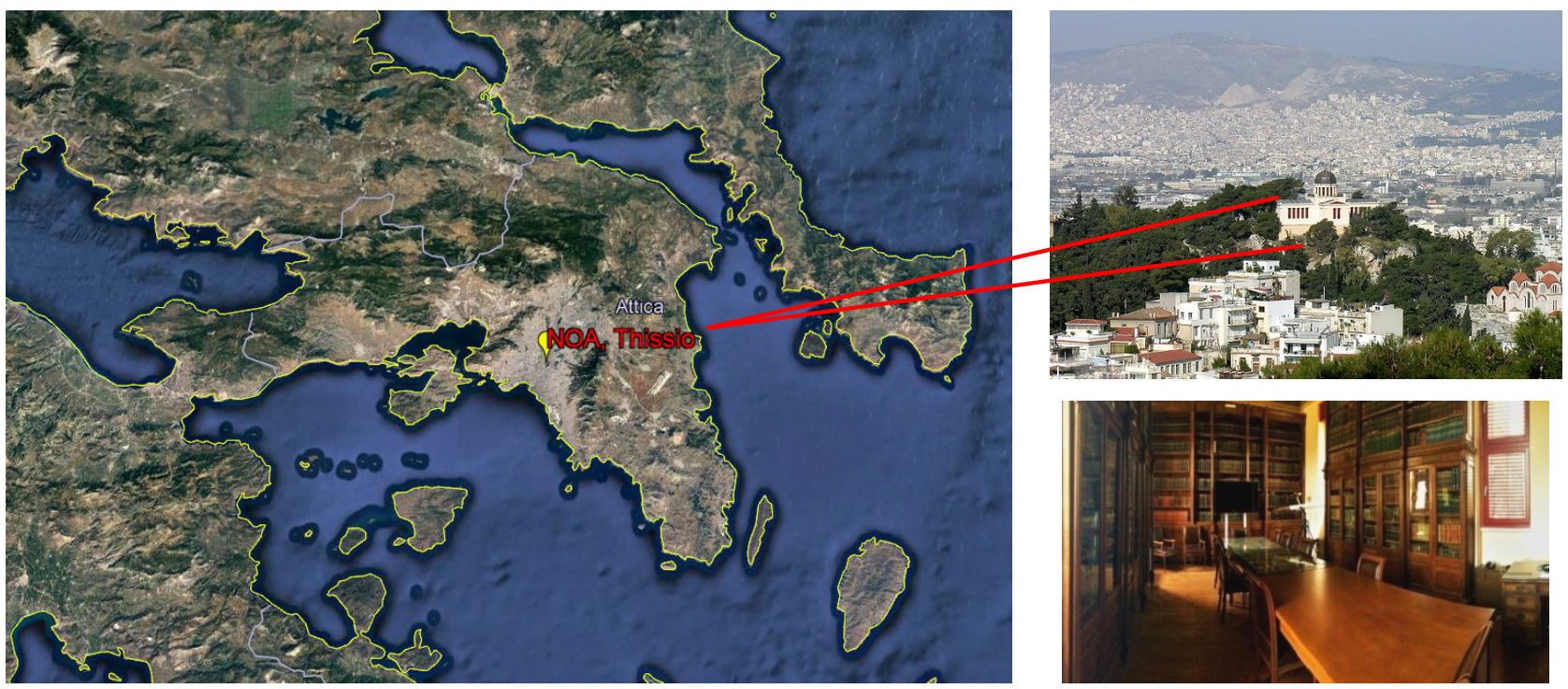

Fig. 1. The location and internal aspect of the NOA library in Athens, Greece.

discoloration, red rot in the leather cover pages, tide lines on the pages suggesting water migration, foxing and mold are further observed. The aforementioned degradation status makes thus necessary the investigation of the decay environmental factors to minimize the material destruction. Books are usually composed of various organic materials of plant and animal origin, resulting in a complex matrix that should optimally be preserved by taking into account the individual requirements of each component. Nevertheless, the book collection of the library can be considered uniform and the risk assessment is focused on paper (pages) and leather (covers), which are the main exposed materials. Other materials found in the library, such as wooden furniture (bookcases, desks, window frames and shutters) and the roof (paint and metal from a ceilingopening mechanism) are not a part of this study with respect to their preservation, and thus possible implications on them will not be further investigated.

\section{Description of the Indoor Air Quality Monitoring Plan and Measurements}

The monitoring was conducted from 4 to 31 August 2016 (26 days) and the period was suitable for the evaluation in terms of atmospheric conditions. During August the regionally originated components (Theodosi et al., 2018; Stavroulas et al., 2019) dominate as a consequence of the summer atmospheric circulation which is quite stable with N/NE air masses accounting for $80 \%$ of the conditions. Moreover, due to the intensive photochemistry in summer and in absence of precipitation, the concentrations of the secondary pollutants $\left(\mathrm{HNO}_{3}, \mathrm{O}_{3}\right.$, aerosols, etc.) could influence the quality of library collections in case of infiltration. They reach their maximum levels and consequently the impact is expected to be enhanced, considering also the high temperatures that could accelerate the decay processes.

For most of the period, the indoor equipment was operated without ventilation or cooling in order to study the targeted parameters' variability under regular conditions encountered in the library as presented above (henceforth referred to as "background period"). On the $11^{\text {th }}, 16^{\text {th }}$ and $18^{\text {th }}$ of August (2016), the air conditioner was operated for a period of 12 hours (8:00 a.m.-8:00 p.m.) in order to investigate the system performance and the variations under cooling conditions (henceforth referred to as "air-conditioned period"). On the $22^{\text {nd }}, 24^{\text {th }}$ and $26^{\text {th }}$ of August (2016), ventilation took place by opening the windows from 9:00 a.m.-10:00 a.m. and 1:00 p.m.-2:00 p.m. (henceforth referred to as "natural ventilation period"). Each of the aforementioned sub-periods is accordingly identified in Tables $\mathrm{S} 1$ and $\mathrm{S} 2$ as $B G, A C$ and $V$ respectively. Despite the fact that during the measurements period the library was isolated for the purposes of our study, the selection of the test time frames was based on the working hours of the library personnel and the usual presence of visitors in the greater area of the observatory, when routine operation and organized daily tours could increase the possibility to open the windows or operate the cooling device. Apart from examining the library room as a whole, a glass-covered showcase table was selected for temperature and relative humidity control monitoring as it contains the most vulnerable publications (from the $16^{\text {th }}$ century).

A Rotronic MP101A-T7-W4W thermo-hygrometer, adjusted to an automated data-logger system, and a Tiny Tag TGP-4500 logger, were operated for the monitoring of relative humidity and temperature in the library and the showcase, respectively, collecting data at 5-minute intervals. The precision of the thermo-hygrometer was $\pm 1 \% \mathrm{RH}$ and $\pm 0.3^{\circ} \mathrm{C}$, while for the showcase logger the respective characteristics are $\pm 3 \% \mathrm{RH}$ and $\pm 0.4^{\circ} \mathrm{C}$ at $20-40^{\circ} \mathrm{C}$. Horiba Analyzers (360 Series) were used to monitor carbon monoxide $(\mathrm{CO})$, nitrogen oxides, sulfur dioxide and ozone $\left(\mathrm{CO}, \mathrm{NO}_{x}=\right.$ $\mathrm{NO}+\mathrm{NO}_{2}, \mathrm{SO}_{2}$ and $\mathrm{O}_{3}$, respectively) at 30-minute resolution. The detection limits of the analyzers are $50 \mathrm{ppb}$ for $\mathrm{CO}$ and $0.50 \mathrm{ppb}$ for the rest of equipment as provided by the manufacturer. Eight indoor particulate matter samples of less than $10-\mu \mathrm{m}$ diameter $\left(\mathrm{PM}_{10}\right)$ were collected on quartz filters by means of a Partisol 2000 FRM sampler with a detection limit of $1.1 \mu \mathrm{g} \mathrm{m}^{-3}$. The filters were pre- and post-weighed in 
the weighing room of the Atmospheric Chemistry Laboratory of NOA, with a 6-digit Mettler Toledo MX-5 balance (of $1-\mu \mathrm{g}$ precision) operating under controlled conditions of temperature and humidity $\left(20 \pm 3^{\circ} \mathrm{C}\right.$ and $\left.40 \pm 5 \% \mathrm{RH}\right)$, for the determination of their mass concentration (Paraskevopoulou et al., 2014). The filters were afterwards analyzed by ion chromatography (ionic composition determination) and by a thermal optical transmission technique for organic and elemental carbon content ( $\mathrm{OC}$ and $\mathrm{EC}$ respectively) at the laboratory of the Chemistry Department of the University of Crete (Novakov et al., 2005; Cavalli et al., 2010; Bougiatioti et al., 2013; Paraskevopoulou et al., 2014). The detection limit of the analysis was 0.26 and $0.05 \mu \mathrm{g} \mathrm{C} \mathrm{cm}{ }^{-2}$ for $\mathrm{OC}$ and $\mathrm{EC}$, whereas for the anions and cations ranges at $20 \mathrm{ppb}$ and $10 \mathrm{ppb}$ respectively. The reported concentrations were corrected for blanks. All of the equipment was calibrated and inter-compared prior to and/or after the measurements in order to ensure the quality of the results. The ambient meteorological and pollutant data that were used for this study are routinely collected at the Thissio Meteorological and Air Pollution Stations located at the central premises of NOA, situated $200 \mathrm{~m}$ and $10 \mathrm{~m}$ respectively from the museum.

\section{RESULTS AND DISCUSSION}

\section{Temperature and Relative Humidity}

In Fig. 2, the outdoor, indoor and showcase measurements of temperature and relative humidity are presented. The airconditioned periods and the natural ventilation periods are marked with red frames and purple lines respectively. Each of these time slots was studied separately and the results of a basic statistical analysis are provided in Tables S1 and S2. The outdoor $\mathrm{T}$ during the campaign ranged between $21.7^{\circ} \mathrm{C}$ and $36.7^{\circ} \mathrm{C}$, with the exception of the period of $13-16$ August, when the average temperature was approximately $3^{\circ} \mathrm{C}$ lower, under the influence of strong northern winds $(\mathrm{N}$, NE, NW direction). During the background period, the average indoor $\mathrm{T}$ was constantly higher by $2.4^{\circ} \mathrm{C}$ compared to relevant outdoor conditions. As shown in Fig. 2(a), on a diurnal basis the outdoor $\mathrm{T}$ was at a maximum at noon and was almost always higher compared to the indoor maximum values for the specific time frame. Nevertheless, the higher amplitude of the outdoor temperature variability resulted in constantly lower outdoor average levels. The stone walls of the library have high thermal inertia which means that during day the material accumulates the heat and later when the temperature drops, it balances the conditions leveling out the indoor variations. The temperature variability in the library and the showcase was similar, with lower levels of $\mathrm{T}$ by $1.1^{\circ} \mathrm{C}$ encountered in the showcase. During the airconditioned period, the temperature in the library and the showcase decreased significantly compared to the outdoor conditions and reached even less than $25^{\circ} \mathrm{C}$. According to Fig. 2(b), the indoor RH presented less variability compared
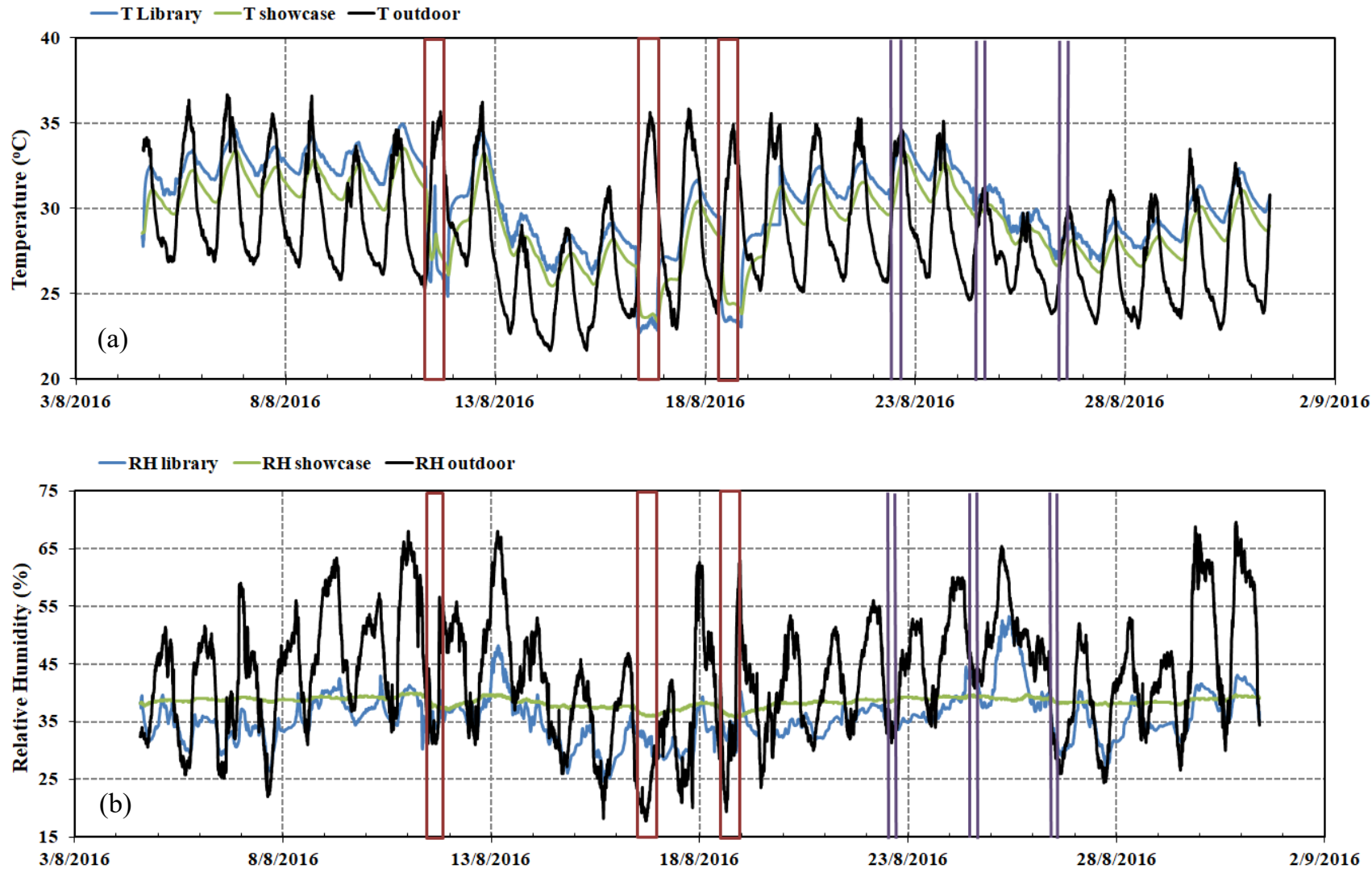

Fig. 2. Variability of (a) temperature and (b) relative humidity for outdoor conditions, the library and the showcase. Red frames and purple lines represent the air-conditioned and natural ventilation periods respectively. The 5-minute values are depicted. 
to the outdoor levels, with observed significant difference in the showcase, which seemed to be independent from outdoor or indoor changes. The average background $\mathrm{RH}$ in the showcase was slightly higher than in the library $(39 \%$ versus $36 \%$ ), still reflecting an insignificant difference between the macro- and micro-environment of the library. The building hosting the library is old (middle of $19^{\text {th }}$ century), made by stone, without interventions on the insulation material of the envelope to now dates and located in an open area enabling the direct impact of the current environmental conditions. Nevertheless, the structural features of the building (i.e., thick stone walls) maintain the $\mathrm{RH}$ at low levels and the hygric inertia ensures moisture balance by limiting relative humidity variations. The low RH variability in the library and the showcase, as well as the consequent smoothening of the short-term fluctuations could be attributed to the buffering capacity of the paper (Kupczak et al., 2018).

To better investigate the T and RH variability during the air-conditioned and natural ventilation periods, each case is magnified in Figs. 3 and 4 respectively. In Fig. 3(a), it is clearly depicted that during the air-conditioned periods (within the red frames) the temperature in the library decreases rapidly, in less than 1 hour, and it remains around $24^{\circ} \mathrm{C}$ as long as the air-conditioning system is in use. On the $11^{\text {th }}$ of August, a sudden increase in $\mathrm{T}$ around noon is attributed to a short interruption of the air-conditioning system operation, with a lesser effect on the showcase's temperature. At noon, the average deviation of the indoor conditions relative to the library and the showcase was in the order of $9-12^{\circ} \mathrm{C}$ and 8 $12^{\circ} \mathrm{C}$ respectively, reflecting similar cooling capability of the air-conditioning system on both the library and the showcase. After the end of the $\mathrm{AC}$ period, the inner temperature recovered to outdoor conditions within an hour. It is also worth noting that while the showcase temperature is lower than in the library by $4 \%$ during background conditions, it remains slightly higher during the air-conditioned time slot by $3-5 \%$ (Table $\mathrm{S} 1$ ), demonstrating the slightly increased direct impact of the forced temperature change on the books on shelves relative to the isolated ones in the showcase. During the air-conditioned periods, the relative humidity in the library (Fig. 3(b)) remained unaffected with respect to its preceding level and higher or almost equal to the outdoor levels, while at background conditions, RH does not exceed the outdoor conditions due to its temperature dependence. In practice, the impact of the domestic air-conditioning system on the library humidity is not significant.

With respect to Fig. 3, Fig. 4 depicts each of the natural ventilation periods magnified for the case of temperature and relative humidity. The variability of the temperature (Fig. 4(a)) inside and outside the library is similar for the ventilation period, but with different rates regarding the temporal change. During the morning ventilation, indoor $\mathrm{T}$ was always higher by up to $2.5^{\circ} \mathrm{C}$ relative to outdoor. It was generally observed that the library temperature tends to decrease at the beginning of the ventilation as heat from the library is transferred out, but afterwards, the temperature is increased following the outdoor trend, but with a 30\% lower rate. Midday levels are almost equal with less than a $0.5^{\circ} \mathrm{C}$ difference on average. Regarding RH in the library (Fig. 4(b)) for the ventilation period, there is no impact on the showcase variability as there was for the case of the air-conditioning operation. For the library, there is an insignificant RH increase at the beginning of morning ventilation due to penetration of the more humid outdoor air masses in the library and then it

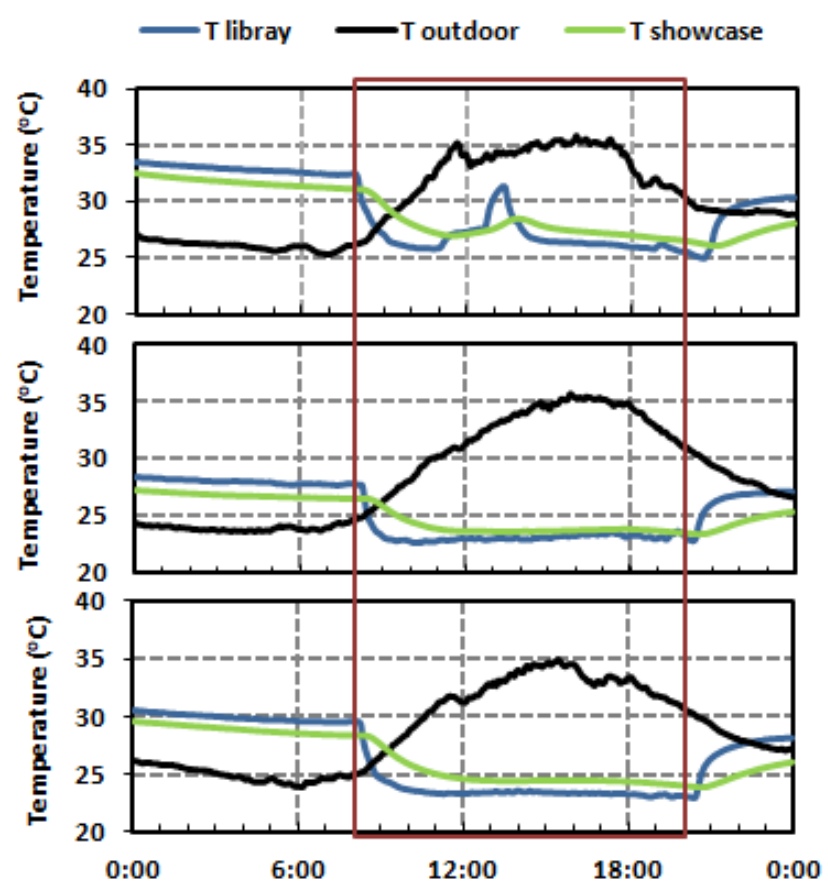

(a)

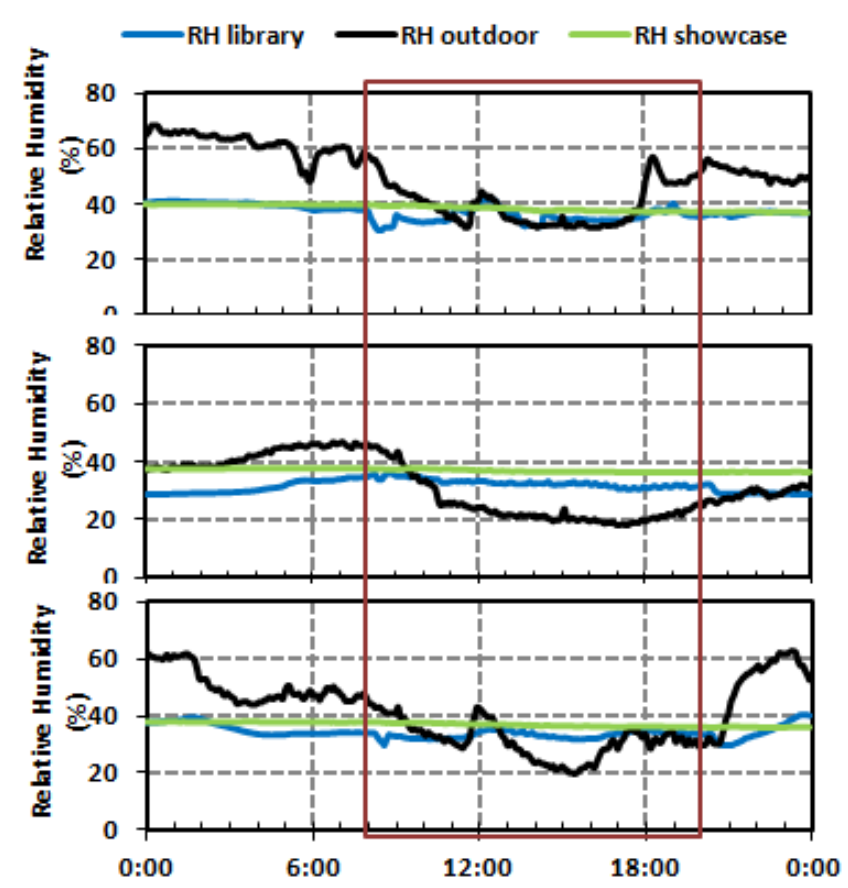

(b)

Fig. 3. Maximized plots of (a) temperature and (b) relative humidity during the air-conditioned periods depicted in red frames on 11 August, 16 August, 18 August (top to bottom) for the period of 8:00 a.m.-8:00 p.m. 


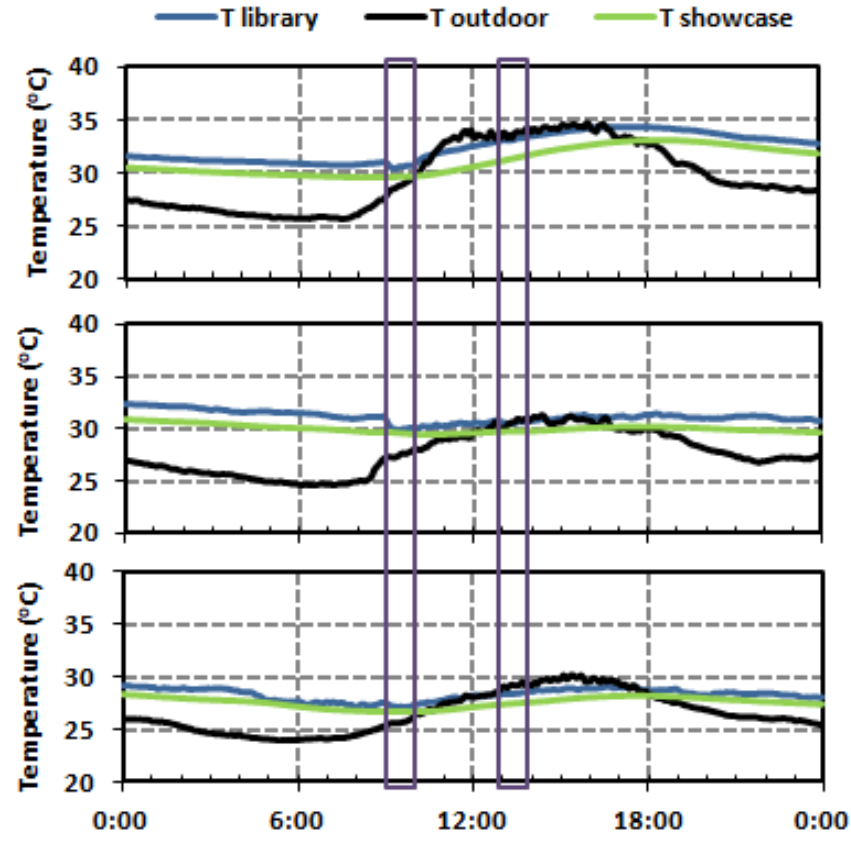

(a)

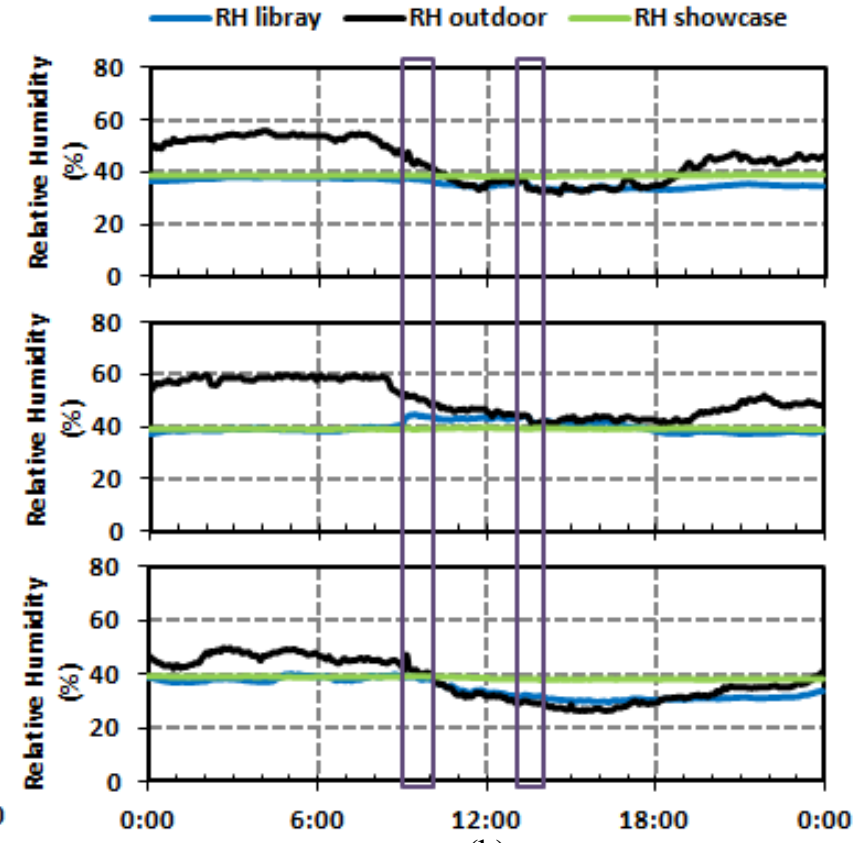

(b)

Fig. 4. Maximized plots of (a) temperature and (b) relative humidity during the ventilation periods depicted in purple frames on 22 August, 24 August, 26 August (top to bottom) during 9:00 a.m.-10:00 a.m. and 1:00 p.m.-2:00 p.m.

is gradually readjusted to almost stable levels throughout the course of ventilation. For the morning ventilation periods, indoor RH was always lower by around 7\% compared to outdoor, whereas midday levels were equivalent.

\section{Indoor Gaseous and Particulate Pollutants}

In Fig. 5, the indoor concentrations of the gaseous pollutants $\mathrm{NO}, \mathrm{NO}_{2}, \mathrm{SO}_{2}, \mathrm{O}_{3}$ and $\mathrm{CO}$ are presented at 30-minute intervals, followed by the outdoor concentrations and the indoor/outdoor $(\mathrm{I} / \mathrm{O})$ ratio when simultaneous measurements were available. The air-conditioned and natural ventilation periods are also marked as done previously. Table 1 summarizes the findings of the parallel indoor-outdoor measurements, including $\mathrm{PM}_{10}$ and the $\mathrm{I} / \mathrm{O}$ ratio for each period. The common variability of both indoor and outdoor pollutant concentrations for $\mathrm{O}_{3}$ and $\mathrm{CO}$ (Fig. 5) clearly indicates that the outdoor levels, as well as emission sources and processes, are driving the library air quality. The outdoor measurements of primary pollutants $(\mathrm{CO})$ were characterized by a morning peak during the traffic rush hours (7:00-9:00 local time) and the increased evening and late night levels, driven by the boundary layer decrease (Alexiou et al., 2018). On the other hand, the photochemically produced $\mathrm{O}_{3}$ levels were elevated around noontime and influenced by the opening of the windows (as also observed by De Santis et al., 1992, for the case of the Galleria degli Uffizi in Florence). Increased levels of pollution were also observed a few days before and after the 15 August public holiday, possibly due to increased traffic (departure and return of Athens' citizens). The relatively strong $\left(>5 \mathrm{~m} \mathrm{~s}^{-1}\right)$ north winds during 13-15 and 24-28 August also resulted in lower levels of the primary pollutants due to more efficient city ventilation processes. Indoor $\mathrm{O}_{3}$ and $\mathrm{CO}$ was lower by
$40 \%$ and $50 \%$, respectively when compared to the outdoor levels during the background period and presented similar temporal variability. No significant changes on the pattern and the relative difference on both indoor and outdoor levels were observed during the air-conditioned periods $\left(11^{\text {th }}, 16^{\text {th }}\right.$ and $18^{\text {th }}$ of August). On the contrary, $\mathrm{O}_{3}$ levels approach the outdoor values while windows were opened, with the relative difference of $8 \%$, on average. In general, an $\mathrm{I} / \mathrm{O}$ ratio $>1$ reflects infiltration and/or additional indoor sources, while low I/O ratios correspond to low inflow (Krupińska et al., 2013). The average $\mathrm{I} / \mathrm{O}$ ratio for both pollutants was $<1$, indicating moderate infiltration and thus limited reactions on the material surfaces after deposition. I/O almost equal to unity (0.9) was observed for $\mathrm{O}_{3}$ during the natural ventilation period attributed to the inflow of the outdoor-originated quantities. The enhanced I/O peaks that have been rarely observed (almost $2 \%$ of the observations) correspond to calculations for periods with low $\mathrm{O}_{3}$ values (due to deposition or NO titration) which contribute to the observed high I/O peaks without significant qualitative impact on the results and the general conclusions regarding the $\mathrm{O}_{3}$ impact.

Information about the 24-hour collected $\mathrm{PM}_{10}$ filter samples is provided in Fig. 6. Similar to gaseous pollutants, the indoor levels were lower relative to outdoors and co-varied (Fig. 6(a)), with means of $19.9 \mu \mathrm{g} \mathrm{m}^{-3}$ and $26.3 \mu \mathrm{g} \mathrm{m}^{-3}$, respectively resulting in a $25 \%$ difference. The $\mathrm{PM}_{10} \mathrm{I} / \mathrm{O}$ ratios for the whole period were lower than 1, ranging from 0.6 to 0.9 and the similar variability indicates that the main factor determining indoor $\mathrm{PM}_{10}$ concentration is outdoor conditions, as in the case of gases. These values indicate the contribution of ambient sources in PM levels inside the library as reported elsewhere (Chianese et al., 2012). The significant indoor-outdoor differences of the $12^{\text {th }}$ and $25^{\text {th }}$ of 


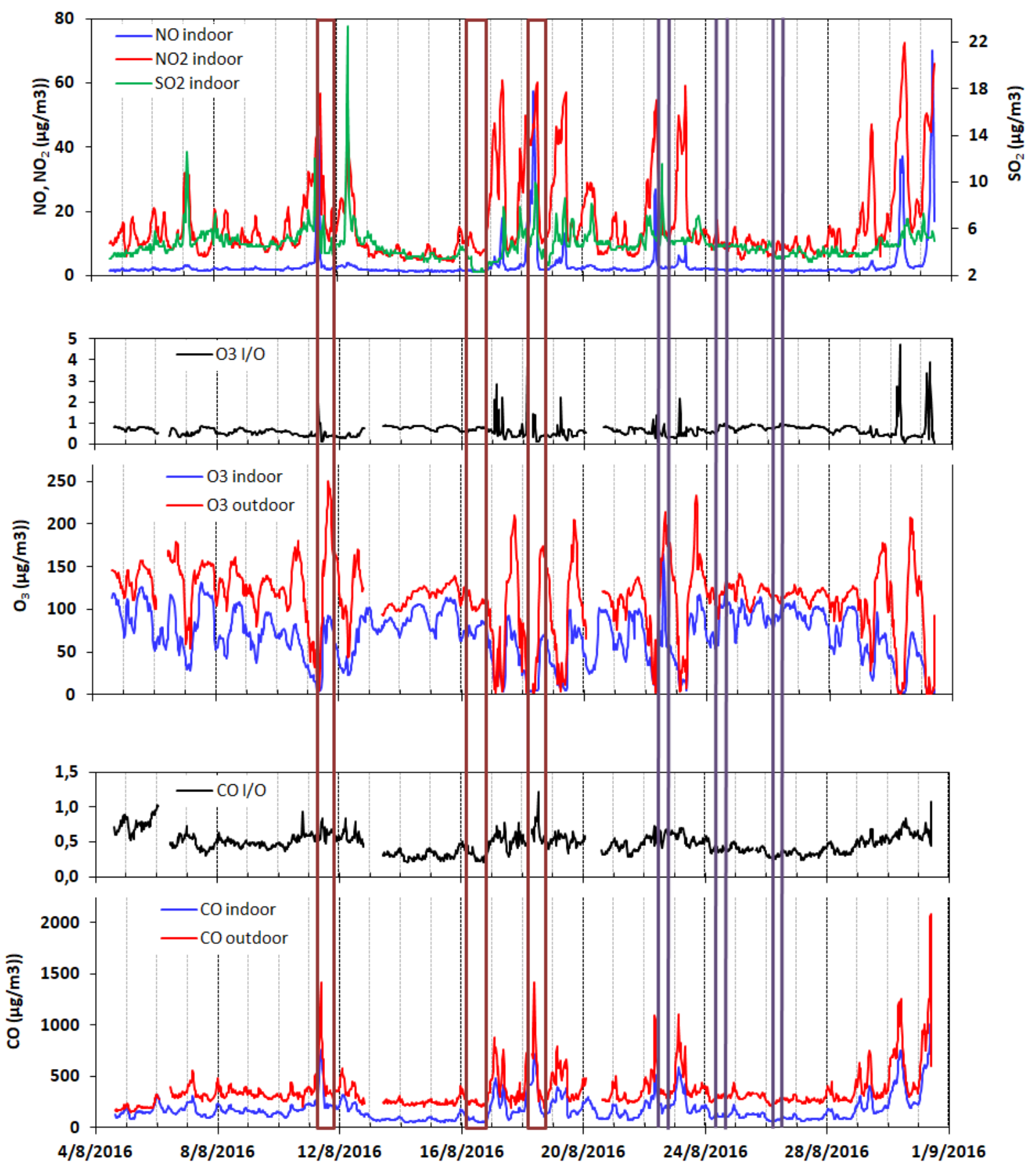

Fig. 5. Indoor and outdoor temporal variability of gaseous pollutants followed by the $\mathrm{I} / \mathrm{O}$ values when available. Red frames and purple lines represent the air-conditioned and natural ventilation periods, respectively.

August corresponds to days with mean wind speed higher than $5 \mathrm{~m} \mathrm{~s}^{-1}$, possibly denoting the slow response time of the building to the forced outdoor conditions, reflecting a kind of equilibrium between the indoor and outdoor relative to the infiltration capacity of particulates.

Apart from the particulate levels, the presence of specific chemical compounds in high concentrations can also be considered as a significant threat to book materials. For this reason and in addition to the main study, chemical characterization of the atmospheric aerosols collected in the library was performed and followed by a mass closure. Dust was calculated by calcium (multiplied by 8 according to Sciare et al., 2005) and particulate organic matter (POM) is equal OC multiplied by 1.8 (Stavroulas et al., 2019). The mass closure (Fig. 6(b)) was almost complete with unknown constituents of $5.4 \%$ and $5.9 \%$ for indoor and outdoor, respectively, which could be attributed to water (Theodosi et al., 2018).

The IC analysis shows that the species which seem to have similar levels both indoors and outdoors (Fig. 6(c)) are secondary species, such as sulfate $\left(\mathrm{SO}_{4}{ }^{2-}\right)$ and nitrate anions $\left(\mathrm{NO}_{3}{ }^{-}\right)$. Primary species, such as elemental carbon, sodium, 
Table 1. Statistics of the indoor and outdoor pollutants' variability followed by their I/O ratio, when available, for each phase of the monitoring period. Values are given in $\mu \mathrm{g} \mathrm{m}^{-3}$. BG, AC and $\mathrm{V}$ correspond to background, air-conditioned and natural ventilation periods, respectively.

\begin{tabular}{|c|c|c|c|c|c|c|c|c|c|c|}
\hline \multirow{2}{*}{ Pollutant } & \multirow{2}{*}{ Statistics } & \multicolumn{3}{|c|}{ Indoor } & \multicolumn{3}{|c|}{ Outdoor } & \multicolumn{3}{|c|}{$\mathrm{I} / \mathrm{O}$} \\
\hline & & BG total & AC total & $\mathrm{V}$ total & BG total & AC total & $\mathrm{V}$ total & BG total & AC total & $\mathrm{V}$ total \\
\hline \multirow[t]{5}{*}{$\mathrm{NO}$} & $\min$ & 0.9 & 1.1 & 1.7 & & & & & & \\
\hline & $\max$ & 70.2 & 57.4 & 5.0 & & & & & & \\
\hline & avg & 2.9 & 8.7 & 2.3 & & & & & & \\
\hline & stdev & 4.8 & 15.0 & 1.0 & & & & & & \\
\hline & med & 2.0 & 2.0 & 2.0 & & & & & & \\
\hline \multirow[t]{5}{*}{$\mathrm{NO}_{2}$} & $\min$ & 4.3 & 6.2 & 8.1 & & & & & & \\
\hline & $\max$ & 72.6 & 60.2 & 46.7 & & & & & & \\
\hline & avg & 15.9 & 21.4 & 16.0 & & & & & & \\
\hline & stdev & 12.3 & 16.9 & 13.1 & & & & & & \\
\hline & med & 11.3 & 12.2 & 10.3 & & & & & & \\
\hline \multirow[t]{5}{*}{$\mathrm{SO}_{2}$} & $\min$ & 2.4 & 2.4 & 3.4 & & & & & & \\
\hline & $\max$ & 23.3 & 10.0 & 11.5 & & & & & & \\
\hline & avg & 4.7 & 4.2 & 5.3 & & & & & & \\
\hline & stdev & 1.3 & 1.8 & 2.4 & & & & & & \\
\hline & med & 4.5 & 3.9 & 4.7 & & & & & & \\
\hline \multirow[t]{5}{*}{$\mathrm{O}_{3}$} & $\min$ & 2.6 & 3.0 & 50.2 & 0.8 & 2.7 & 60.8 & 0.1 & 0.1 & 0.7 \\
\hline & $\max$ & 144.1 & 93.0 & 165.2 & 233.5 & 250.0 & 171.4 & 4.8 & 1.4 & 1.0 \\
\hline & avg & 69.9 & 59.3 & 107.9 & 113.6 & 120.8 & 118.4 & 0.7 & 0.5 & 0.9 \\
\hline & stdev & 30.6 & 30.1 & 27.2 & 39.6 & 62.5 & 29.8 & 0.3 & 0.3 & 0.1 \\
\hline & med & 73.7 & 69.2 & 106.0 & 119.4 & 110.5 & 115.8 & 0.6 & 0.4 & 0.9 \\
\hline \multirow[t]{5}{*}{$\mathrm{CO}$} & $\min$ & 49.3 & 49.3 & 73.9 & 147.3 & 189.3 & 259.0 & 0.2 & 0.2 & 0.3 \\
\hline & $\max$ & 1009.8 & 763.5 & 344.8 & 2083.5 & 1415.4 & 645.5 & 1.1 & 1.2 & 0.5 \\
\hline & avg & 176.7 & 232.3 & 145.7 & 355.2 & 408.2 & 348.2 & 0.5 & 0.5 & 0.4 \\
\hline & stdev & 115.3 & 204.3 & 81.2 & 172.9 & 280.3 & 119.4 & 0.1 & 0.2 & 0.1 \\
\hline & med & 147.8 & 172.4 & 117.0 & 310.3 & 307.2 & 307.8 & 0.5 & 0.5 & 0.4 \\
\hline \multirow[t]{5}{*}{$\mathrm{PM}_{10}$} & $\min$ & 13.6 & & & 15.5 & & & 0.6 & & \\
\hline & $\max$ & 24.4 & & & 38.1 & & & 0.9 & & \\
\hline & avg & 19.9 & & & 26.3 & & & 0.8 & & \\
\hline & stdev & 3.8 & & & 6.7 & & & 0.1 & & \\
\hline & med & 20.5 & & & 25.9 & & & 0.8 & & \\
\hline
\end{tabular}

magnesium, calcium and to a lesser extent the photochemically produced oxalate ions (EC, $\mathrm{Na}^{+}, \mathrm{Mg}^{2+}, \mathrm{Ca}^{2+}$ expressed as dust and $\mathrm{O}_{x}^{-}$, respectively), were found at higher levels outside, relative to the indoor library area. The most abundant species inside the museum was POM; and with dust and sulfates make up for almost $80 \%$ of the total mass with relative contributions of $37.1 \%, 21.1 \%$ and $20.4 \%$, respectively. Enhanced levels of organic matter were also reported in other cultural heritage indoor environments (e.g., Cappitelli et al., 2009; Mascova et al., 2015). The predominant contribution of the sulfates, for the ionic components, is in agreement with findings at indoor cultural heritage environments (Cao et al., 2011; Xiu et al., 2015; Bartl et al., 2016; Uring et al., 2018); whereas, according to publications calcium-rich particles have been determined to dominate the indoor aerosol in museums depending on the wall material (Camuffo et al., 1999, 2001) or restoration and construction works (Gysels et al., 2004), without excluding outdoor sources (Gysels et al., 2002). The same stands for outdoors despite the prevalence of dust relative to POM with $42.5 \%$ against $22.6 \%$. Outdoor soil re-suspension enhances the dust levels but these relatively big particles do not penetrate into the library, resulting thus in lower indoor levels of dust. The contribution (maximum $<5 \%$ ) of the rest of the compounds is of less importance relative to these three factors $\left(\mathrm{SO}_{4}{ }^{2-}, \mathrm{POM}\right.$, dust). By examining their absolute indoor and outdoor levels, important differences on the resulting I/O occurred (Fig. 6(c)). Higher-than-unity I/O was observed for POM, ammonium, potassium, and chloride, while sulfates and nitrates were close to unity. Emissions of organic material and microbial activity indoors could drive the enhanced levels of POM and ammonium. On the other hand, enhanced levels of chloride and potassium levels indoors could be associated with emissions from cleaning materials and dust, respectively. The source apportionment based on inter-correlations of such a short-term dataset provides relatively limited results. The resulting correlations were weak with the exception of sodium relative to magnesium $\left(\mathrm{R}^{2}=0.91\right.$ indoor and 0.94 outdoor) and sodium relative to chloride and magnesium indoor $\left(\mathrm{R}^{2}>0.86\right)$. Indeed, salts such as $\mathrm{NaCl}$ and $\mathrm{MgCl}_{2}$ (Anaf et al., 2014) could be present indoors, denoting an impact of sea salt (transport for our case) or building materials, respectively (mortars according to Krupińska et al., 2013). 
(a)
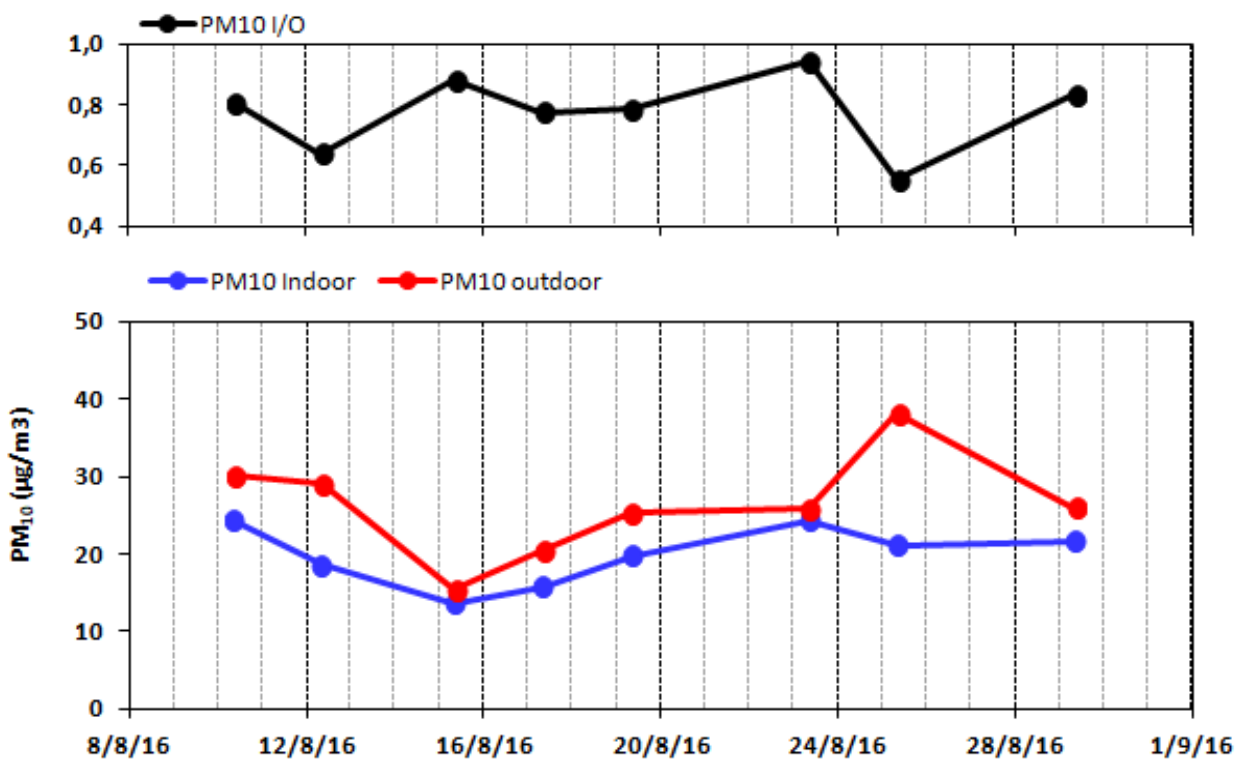

(b)
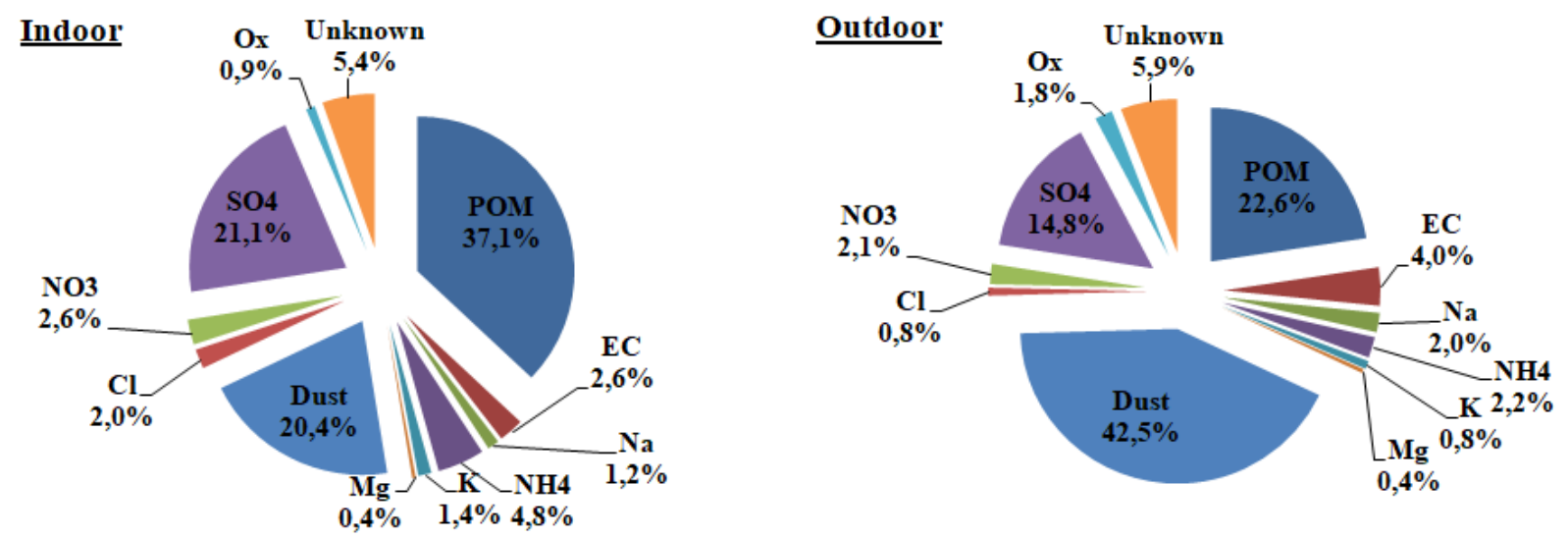

(c)
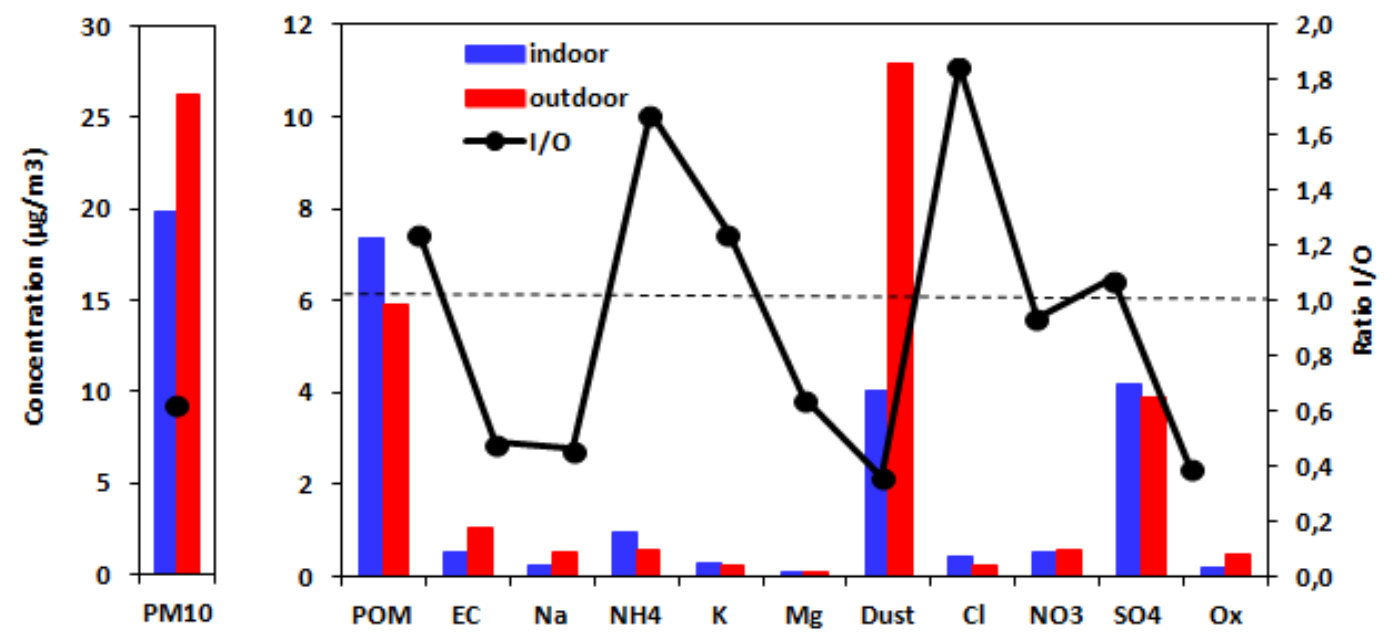

Fig. 6. Indoor-outdoor relations of (a) the $\mathrm{PM}_{10}$ mass concentration of filter samples on 24-hour basis, (b) the mass closure and (c) the mean chemical composition, over the experimental period.

\section{Risk Assessment of Temperature and Relative Humidity on the Books Collection}

The longer lifetime of paper material is achieved at lowmoderate temperatures and moderate relative humidity levels (Adcock, 1998). The best practice is to regulate and stabilize the conditions, to the extent possible, as to avoid sharp fluctuations that put stress on the exposed materials. With respect to preservation, norms that nominate an optimum level or range of levels for the materials' exposure conditions are applied, by making a compromise between the optimal 
choices for conservation purposes and what is considered affordable. While the lowest acceptable humidity level for long-term storage of archival and library materials is, in general, under discussion and many reference levels or norms are used, the type of the material, the manufacturing process and the preservation state of the object, determine the selection of the applied limit values (Blades et al., 2000; Brown et al., 2002; Andreopoulou-Magkou and Mariolopoulos, 2005; Kite and Thomson, 2006). The limit values of $21 \pm 1^{\circ} \mathrm{C}$ and $50 \pm$ $3 \%$ RH, which were introduced in 1979 (La Fontaine, 1979), are still often considered to be the reference limits to avoid book deterioration (Table 2). The classic reference values for conservation conditions, according to Thomson (1994), are a temperature set to $20^{\circ} \mathrm{C}$ and a relative humidity of $50 \%$. A slight change to $18^{\circ} \mathrm{C}$ and $45 \%$ RH (recommended by Davis, 2006) can significantly increase the lifetime of certain types of materials. Based on the best available knowledge and the specifications for collections included in the 2015 ASHRAE Handbook (American Society of Heating Refrigeration and Air-Conditioning Engineers, 2015), the limit values of 50\% $\mathrm{RH}$ and a temperature range of $15-25^{\circ} \mathrm{C}$ can be adopted for sensitive materials. The tolerance is a bit higher for general collections, reaching $60 \% \mathrm{RH}$ and temperatures within 20 $30^{\circ} \mathrm{C}$. The International Standard ISO 11799:2003, "Information and documentation-Document storage requirements for archive and library materials," applies to the long-term storage of archive and library materials and also points out that repositories for such materials should be kept at a cool temperature and at a relative humidity below the point where microbiological activity occurs. Despite the relative unanimity about the decay of paper under constant $\mathrm{T}$ and $\mathrm{RH}$, there is still discussion about the mechanisms that fluctuating environmental conditions impact on the chemical and physical properties of the specific substrate. In the review of Menart et al. (2011) degradation of paper under cyclic conditions of T and/or RH (Shahani et al., 1989; Bogaard and Whitmore, 2002; Panek et al., 2004) is reported, whereas the time spent under each condition is determinant for the impact on the material (Bigourdan and Reilly, 2002). Nevertheless, mild changes in T and RH could be buffered by books stored closely together (Henderson, 2007), as in our case.

In this study, the recommended range defined in ISO 11799:2003 are used in combination with the limitations recently published by Andretta et al. (2016) in accordance with UNI 10586:1997 (Table 2), leading to a combined range of $2-20^{\circ} \mathrm{C}$ and $30-60 \% \mathrm{RH}$, covering limitations for paper and leather. According to Fig. 2 and Table S1, temperature limits were exceeded during the background period in the library and the showcase, with values constantly above the upper limit of $20^{\circ} \mathrm{C}$ provided by the two aforementioned references. The minimum temperature in the library was also above the upper acceptable limit. Opposite to temperature, the indoor relative humidity fell within the proposed limits for paper preservation, but was lower than what is recommended for the preservation of the leather bindings of the books. Fig. 7 presents the 24-hour difference between the minimum and maximum of the measured indoor temperature and relative humidity ( $\Delta T_{24}$ and $\Delta R H_{24}$ respectively). The airconditioned and the natural ventilation periods are depicted within the frames in Fig. 7 and are excluded by the risk assessment as they correspond to forced conditions. Both tolerable daily changes of $1^{\circ} \mathrm{C}$ and $3 \% \mathrm{RH}$ of the ISO 11799:2003 and $2{ }^{\circ} \mathrm{C}$ and 5\% RH according to Andretta et al. (2016) were considered. Regardless of the chosen norms, the indoor (library and showcase) gradient for temperature was above the limits during the majority of days. The RH gradient for the showcase was within the suggested limits, but exceedances were encountered almost every day for the library.

The Performance Index (PI) of the building, which expresses the percentage of time in which the microclimatic parameters of the library do not match the recommended values, is calculated in order to evaluate the indoor microclimatic quality (IMQ) (Corgnati et al., 2009). The values of both parameters, $\mathrm{T}$ and $\mathrm{RH}$, obtained in the library and the glassfronted showcase measured in 5-minute intervals were used in Fig. 8, where the green lines are the acceptable limits for storage according to ISO $11799: 2003\left(2-18^{\circ} \mathrm{C}\right.$ and $\left.30-60 \%\right)$ and the red lines are the acceptable limits according to Andretta et al. (2016) $\left(14-20^{\circ} \mathrm{C}\right.$ and 50-60\%). In the optimal case, the pairs of $\mathrm{T}$ and $\mathrm{RH}$ should be within the colorful areas defined by these limits. Despite the fact that $\mathrm{RH}$ individually was in general considered acceptable, this synergistic tool highlights an important issue in our case. According to the findings, the conditions in the library and the showcase during the studied period are completely out

Table 2. Summary of preservation reference values for relative humidity and temperature for books and archival material. Text in italics corresponds to the norms that were utilized in this manuscript.

\begin{tabular}{llll}
\hline Standard/Reference & Conditions/Material & Temperature & Relative Humidity \\
\hline La Fontaine (1979) & Limits for deterioration of materials & $21 \pm 1{ }^{\circ} \mathrm{C}$ & $50 \pm 3 \%$ \\
Thomson (1994) & Classic reference conservation conditions & $20^{\circ} \mathrm{C}$ & $50 \%$ \\
Davis (2006) & Updated recommended parameters & $18^{\circ} \mathrm{C}$ & $45 \%$ \\
ASHRAE (2015) & Sensitive materials & $15-25^{\circ} \mathrm{C}$ & $<50 \%$ \\
& General collections & $20-30^{\circ} \mathrm{C}$ & $<60 \%$ \\
ISO 11799:2003 (archival book & Paper (optimum preservation) & $2-18 \pm 1^{\circ} \mathrm{C}^{\mathrm{a}}$ & $30-45 \pm 3 \%$ \\
material) & Paper (staffed stack areas, items in regular use) & $14-18 \pm 1^{\circ} \mathrm{C}^{\mathrm{a}}$ & $35-50 \pm 3 \% \mathrm{a}$ \\
& Leather & $2-18 \pm 1^{\circ} \mathrm{C}^{\mathrm{a}}$ & $50-60 \pm 3 \% R H^{\mathrm{a}}$ \\
UNI 10586, Andretta et al. (2016) & Librarian artifacts & $14-20^{\circ} \mathrm{C}$ & $50-60 \%$ \\
& & $\Delta T_{24}<2^{\circ} \mathrm{C}$ & $\Delta R H_{24}<5 \%$ \\
\hline
\end{tabular}

a Tolerable daily changes within the limits. 

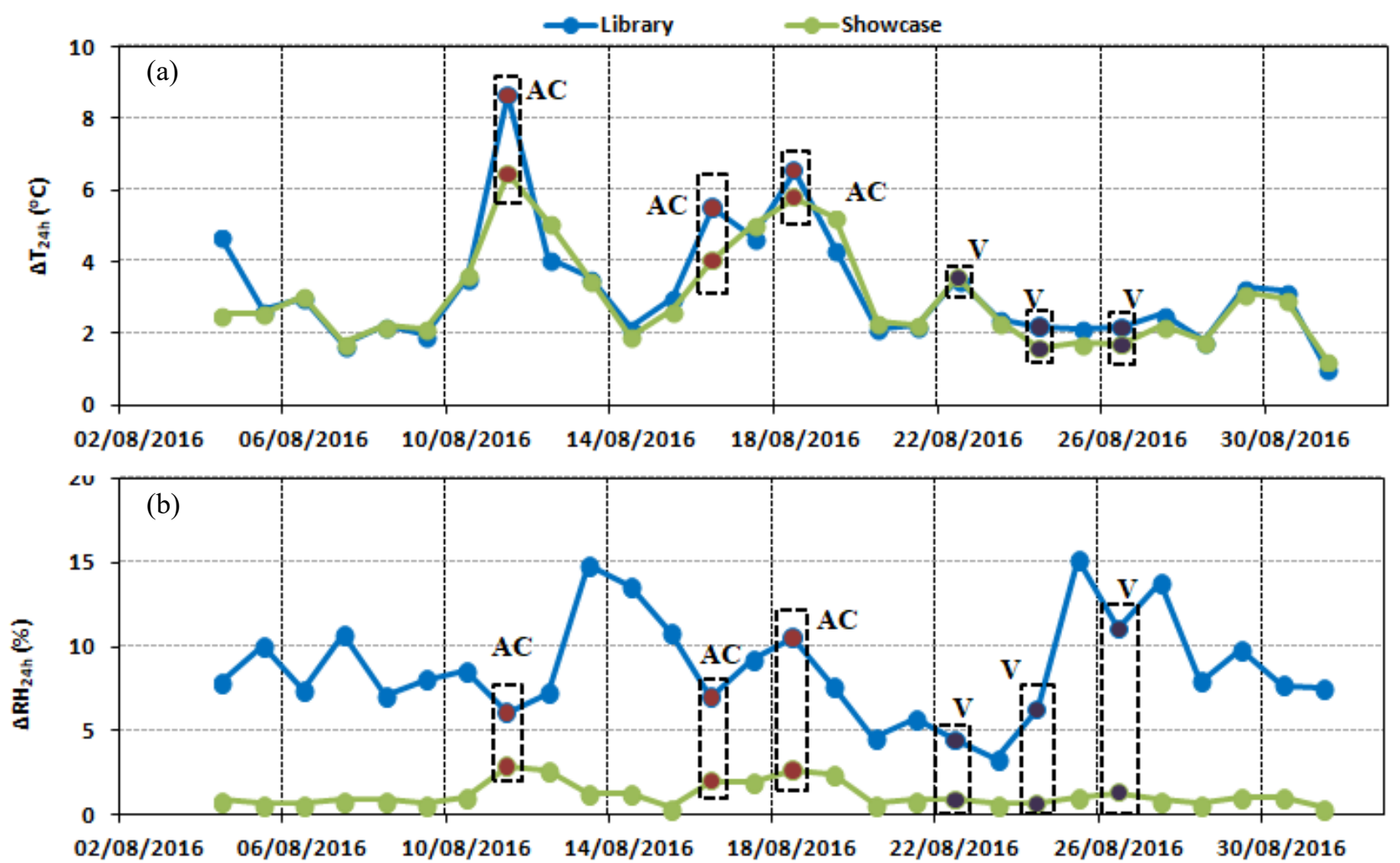

Fig. 7. Daily gradients ( $\max -\min$ ) for (a) temperature and (b) relative humidity during the experimental period in the library. The black frames represent the days that the air library was either air-conditioned or naturally ventilated.

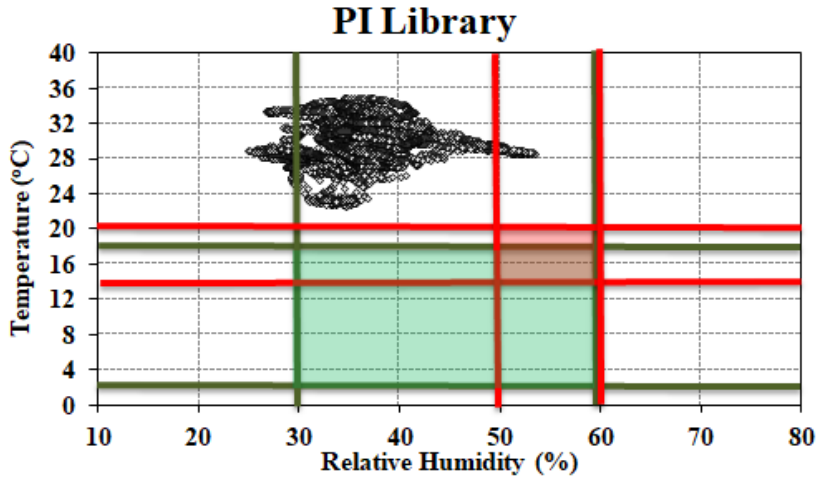

(a)

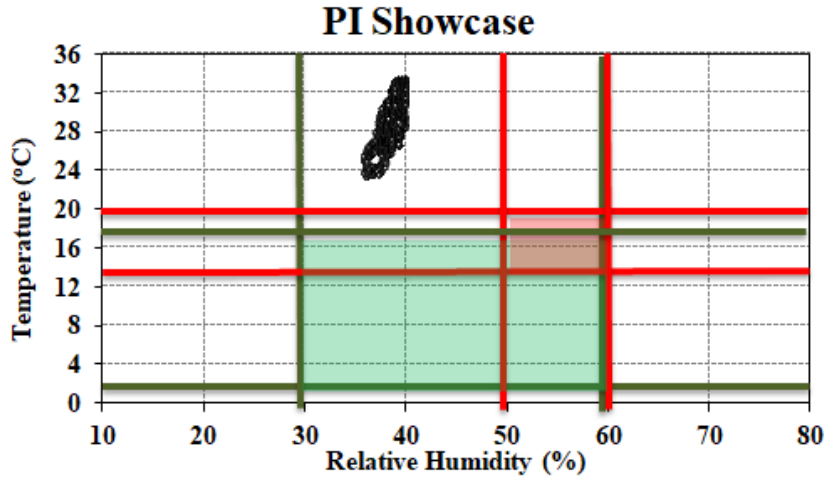

(b)

Fig. 8. Performance Index (PI) for the experimental period according to temperature and relative humidity measured in (a) the library and (b) the showcase in 5-minute intervals. The green lines are the extended acceptable limits for book materials storage according to ISO $11799: 2003\left(2-18^{\circ} \mathrm{C}\right.$ and 30-60\%) and the red lines are the limits according to Andretta et al. (2016) $\left(14-20^{\circ} \mathrm{C}\right.$ and $\left.50-60 \%\right)$.

of control, demonstrating the poor capability of the building to regulate indoor conditions without an HVAC system, thus posing a risk to the collection of books. Over time, the high temperatures that have occurred in the room and the sharp daily gradients of both temperature and relative humidity could justify the observed discoloration and fragility of the books. It is worth noting that the books are stored under the specific environmental conditions for at least ten years, providing thus an acclimatization period for the evaluation of the historical climate (BS EN 15757:2010). Nevertheless, the current status of the books could also have been affected by the storage conditions prevailing before 2008 (i.e., before the reconstruction).

\section{Risk Assessment of Air Pollution on the Book Collection}

With reference to the currently recommended levels of key gaseous pollutants for collections included in the 2015 ASHRAE Handbook for sensitive materials, the limit values for $\mathrm{NO}_{2}$ range from 0.09 to $4.89 \mu \mathrm{g} \mathrm{m}^{-3}$, for $\mathrm{SO}_{2}$ from 0.1 to $1.05 \mu \mathrm{g} \mathrm{m}^{-3}$ and $\mathrm{O}_{3}$ is less than $0.1 \mu \mathrm{g} \mathrm{m}^{-3}$. Taking into 
consideration the general collection guidelines, the limits are set at 3.76-18.82, 1.05-5.24 and 0.98-9.82 $\mu \mathrm{g} \mathrm{m}^{-3}$ for $\mathrm{NO}_{2}$, $\mathrm{SO}_{2}$ and $\mathrm{O}_{3}$, respectively (Table 3 ). On the other hand, according to ISO 11799:2003, the concentration of pollutants in areas dedicated for books and archival material storage is set at higher levels even by one order of magnitude. According to Table 1 , the average levels of $\mathrm{NO}_{2}$ and $\mathrm{SO}_{2}$ of $15.9 \mu$ and $4.7 \mu \mathrm{g} \mathrm{m}^{-3}$ respectively, are close to the ASHRAE guidelines for general collections but the min-max variability deviates significantly. Furthermore, our findings were within the limits of ISO 11799:2003 for $\mathrm{SO}_{2}$, but extremely higher than the acceptable limit for $\mathrm{O}_{3}$, regardless of the norms used and could be related to degradation of the leather components of the books. Concerning $\mathrm{PM}_{10}$, no reliable conclusions could be deduced since there is no reference for the specific monitored fraction. The indoor levels of the gaseous species, which are higher than the suggested levels, may have a synergistic role with the thermo-hydrometric parameters, contributing to the decay of the books and their current status.

\section{CONCLUSIONS}

The temperature and relative humidity, as well as the concentrations of major air pollutants (viz., $\mathrm{NO}_{x}, \mathrm{O}_{3}, \mathrm{SO}_{2}$, $\mathrm{CO}$ and $\mathrm{PM}_{10}$ ), in the library hosted by the Museum of Geoastrophysics of the National Observatory of Athens were monitored for 1 month during the summer, a period representing conditions in this city when the primary pollution background is highly influenced by regional emission sources and which is associated with high temperatures and secondary pollutant formation. Measurements were performed both in the library room and outdoors to determine the indoor-outdoor interactions during natural and artificial ventilation of the building. Also, to assess the risk posed by the IAQ to the library's book collection, we compared our findings to previously published reference values and applied existing tools for evaluating the effect of micro-environmental conditions on cultural heritage artifacts.

Higher mean temperatures were encountered inside the library and the showcase than outdoors, and similar diurnal profiles between these locations reflected the building's inability to offset environmental changes. Operating the air conditioning decreased the temperature, but the effect of opening the windows was limited. On the other hand, the relative humidity was less influenced by the outdoor conditions and remained at almost stable levels in the showcase, regardless of the cooling method. Furthermore, the temperature continuously exceeded the recommended maximum limit of $20^{\circ} \mathrm{C}$, whereas the relative humidity fell within the acceptable range for paper conservation. Nevertheless, the simultaneous investigation of both parameters using the performance index (PI) of the building revealed that conditions in the library and the showcase during the study period were consistently far from optimal and potentially damaging to the book collection. The books were also vulnerable to the intensive daily changes in temperature that occurred both during normal conditions and due to short periods of air conditioning.

Regarding the pollutants, the day-to-day variability of the
I/O ratio may indicate changes in the air penetrating the building, which depends on factors such as the outdoor wind speed and the structural characteristics of the building. Although $\mathrm{O}_{3}$ and dust infiltrated the library more easily when the windows were open, these risk factors were considered to be minor during the library's normal operating conditions, which are defined as having closed doors and windows with a limited human presence. The average I/O ratio for both gaseous and particulate pollutants was less than 1, indicating low infiltration and minimal deposition processes and reactions on the materials' surfaces. However, in absolute terms, the levels of ozone inside the library greatly exceeded any applicable limit for $\mathrm{O}_{3}$, even though all of the other monitored pollutants displayed acceptable average concentrations. Nevertheless, the fluctuations in $\mathrm{NO}_{2}$ and $\mathrm{SO}_{2}$ should be taken into account, as they may be partially responsible for the observed discoloration, embrittlement and fragility of some of the books in the library.

Additionally, the atmospheric aerosols collected in the library were chemically characterized. The measured chemical species (viz., the major ions and organic and elemental carbon) and their I/O ratios can be divided into three categories: i) Primary species from both natural and anthropogenic sources, such as elemental carbon, sodium, magnesium and calcium, exhibited higher concentrations outside than inside the library $(\mathrm{I} / \mathrm{O}<1)$. ii) Secondary species related to longrange transport, such as $\mathrm{SO}_{4}{ }^{2-}$ and $\mathrm{NO}_{3}{ }^{-}$, exhibited an $\mathrm{I} / \mathrm{O}$ ratio close to unity. iii) Lastly, POM, ammonium, potassium and chloride (related to organic material, microbial activity and indoor emissions from cleaning materials and dust) exhibited an $\mathrm{I} / \mathrm{O}$ ratio above unity (i.e., $\mathrm{I} / \mathrm{O}>1$ ).

According to our findings, outdoor conditions strongly influenced both the chemical profiles, especially for the gaseous species, and the microclimatic parameters in the library, demonstrating the poor ability of the building to regulate the indoor environment. We also evaluated the normal ventilation practices in the library and discovered that neither operating the air conditioning nor opening the windows for short periods of time affected the relative humidity indoors, which remained almost stable regardless of the conditions. As both the library and the showcase responded to forced temperature changes, the frequent use of a cooling device, which produces sharp fluctuations in the ambient temperature, is not recommended. Additionally, opening the windows at noon is not recommended because of the higher outdoor temperatures and the potential transport of photochemically produced, reactive pollutants, such as $\mathrm{O}_{3}$. Instead, short periods of natural ventilation during the morning, which dissipate the heat load and increase the comfort of individuals inside the library, are preferred. At minimum, ideal improvements to the library environment include protective shelves that prevent the deposition of dust and other contaminants on the books. A continuously operated air-conditioning system should also be integrated into the environment to maintain the temperature within the recommended limits, to suppress sharp variations caused by outdoor conditions and to inhibit the degradation - thermal, primarily, and chemical and biochemical, secondarily-of the paper and leather components of the books. In summary, 
the microclimatic conditions, which appear to be the crucial decay factor at the library of the Museum of Geoastrophysics of the National Observatory of Athens, should be regulated, continuously monitored in the future and synergistically investigated in order to evaluate their combined effects on the book collection.

\section{ACKNOWLEDGMENTS}

This study forms part of the diploma thesis of FD within the MSc course "CultTech" at the Department of History, Archaeology and Cultural Resources Management of the University of Peloponnese. The authors acknowledge the funding received by ERA-PLANET (www.era-planet.eu), trans-national project SMURBS (www.smurbs.eu) (Grant Agreement No. 689443), funded under the EU Horizon 2020 Framework Programme. The authors also thank the staff of the library of the Museum of Geoastrophysics of the National Observatory of Athens for their support and the Environmental Chemical Processes Laboratory in the Chemistry Department of the University of Crete for the chemical analysis of the filter samples.

\section{DISCLAIMER}

The authors declare no conflict of interest.

\section{SUPPLEMENTARY MATERIAL}

Supplementary data associated with this article can be found in the online version at http://www.aaqr.org.

\section{REFERENCES}

Adcock, E.P. (1998). IFLA Principles for the Care and Handling of Library Material. CLIR, Washington DR, IFLA PAC, Paris.

Alexiou, D., Kokkalis, P., Papayannis, A., Rocadenbosch, F., Argyrouli, A., Tsaknakis, G., Tzanis, C.G., Makoto, A., Vassilis, A., Balis, D., Behrendt, A., Comeron, A., Gibert, F., Landulfo, E., McCormick, M.P., Senff, C., Veselovskii, I. and Wandinger, U. (2018). PPlanetary boundary layer height variability over athens, greece, based on the synergy of raman lidar and radiosonde data: Application of the kalman filter and other techniques (2011-2016). EPJ Web Conf. 176: 06007.

Anaf, W., Bencs, L., Van Grieken, R., Janssens, K. and DeWael, K. (2014). Indoor particulate matter in four Belgian heritage sites: Case studies on the deposition of dark-colored and hygroscopic particles. Sci. Total Environ. 506-507: 361-368.

Andreopoulou-Magkou, E. and Mariolopoulos, T. (2005). Leather: Structure, Technology, Deterioration, Conservation, Analyses, ION, Athens.

Andretta, M., Coppola, F. and Seccia, L. (2016). Investigation on the interaction between the outdoor environment and the indoor microclimate of a historical library. J. Cult. Heritage 17: 75-86.

Ankersmit, B. and Stappers, M. (2016). Managing Indoor
Climate risks in Museums, Springer, Switzerland.

Area, M.C. and Cheradame, H. (2011). Paper aging and degradation: Recent findings and research methods. BioRes 6: 5307-5337.

ASHRAE Handbook (2015). Heating, Ventilating and Airconditioning Applications, SI Edition, Atlanta.

Athanasopoulou, E., Speyer, O., Brunner, D., Vogel, H., Vogel, B., Mihalopoulos, N. and Gerasopoulos, E. (2017). Changes in domestic heating fuel use in Greece: Effects on atmospheric chemistry and radiation, Atmos. Chem. Phys. 17: 10597-10618.

Bartl, B., Maskova, L., Paulusova, H., Smolik, J., Bartlova, L. and Vodicka, P. (2016). The effect of dust particles on cellulose degradation. Stud. Conserv. 61: 203-208

Bigourdan, J.L. and Reilly, J.M. (2002). Effects of fluctuating environments on paper materials e stability and practical significance for preservation. La conservation à l'ère du numérique: actes des quatrièmes journées internationales d'études de l'ARSAG, 27-30 May 2002, Paris, France, pp. 180-92.

Blades, N., Oreszczyn, T., Bordass, W. and Cassar, M. (2000). Guidelines on Efficient Pollution Control in Heritage Buildings, Source the Council for Museums, Archives and Libraries.

Bogaard, J. and Whitmore, P.M. (2002). Explorations of the role of humidity fluctuations in the deterioration of paper. Works of art on paper, books, documents and photographs: Techniques and conservation. Contributions to the Baltimore congress, London, UK. 2-6 September 2002, pp. 11-15.

Bougiatioti, A., Zarmpas, P., Koulouri, E., Antoniou, M., Theodosi,C., Kouvarakis, G., Saarikoski, S., Makela, T., Hillamo, R. and Mihalopoulos, N. (2013). Organic, elemental and water-soluble organic carbon in size segregated aerosols, in the marine boundary layer of the Eastern Mediterranean, Atmos. Environ. 64: 251-262.

Brown, S., Cole, I., Daniel, V. and King, S. (2002). Guidelines for Environmental Control in Cultural Institution, Heritage Collections Council.

BS EN 15757:2010. Conservation of cultural property. Specifications for temperature and relative humidity to limit climate-induced mechanical damage in organic hygroscopic materials. British-Adopted European Standard.

Camuffo, D., Brimblecombe, P., Van Grieken, R., Busse, J.H., Giovanni Sturaro, G., Valentino, A., Bernardi, A., Blades, N., Shooter D., De Bock, D., Gysels, K., Wieser, M. and Kim, O. (1999). Indoor air quality at the Correr Museum, Venice, Italy. Sci. Total Environ. 236: 135-152. Camuffo, D., Van Grieken, R., Busse, H.J., Sturaro, G., Valentino, A., Bernardi, A., Blades, N., Shooter, D., Gysels, K., Deutsch, F., Wieser, M., Kim, O. and Ulrych, U. (2001). Environmental monitoring in four European museums. Atmos. Environ. 35: 127-140.

Cao, J., Li, H., Chow, J.C., Watson, J.G., Lee, S., Rong, B., Dong, J. and Ho, K. (2011). Chemical composition of indoor and outdoor atmospheric particles at emperor Qin's Terra-cotta Museum, Xi'an, China. Aerosol Air Qual. Res. 11: 70-79.

Cappitelli, F., Fermo, P., Vecchi, R., Piazzalunga, P., Valli, 
G., Zanardini, E. and Sorlini, C. (2009). Chemicalphysical and microbiological measurements for indoor air quality assessment at the Ca'Granda Historical Archive, Milan (Italy). Water Air Soil Pollut. 201: 109-120.

Cavalli, F., Viana, M., Yttri, K.E., Genberg, J. and Putaud, J.P. (2010). Toward a standardised thermal-optical protocol for measuring at-mospheric organic and elemental carbon: The EUSAAR protocol. Atmos. Meas. Tech. 3: 79-89.

Chianese, E., Riccio, A., Duro, I., Trifuoggi, M., Iovino, P., Capasso, S. and Barone, G. (2012). Measurements for indoor air quality assessment at the Capodimonte Museum in Naples (Italy). Int. J. Environ. Res. 6: 509-518.

Corgnati, S.P., Fabi, V. and Filippi, M. (2009). A methodology for microclimatic quality evaluation in museums: Application to a temporary exhibit. Build. Environ. 44: 1253-1260.

Daniel, F., Flieder, F. and Leclerc, F. (1990). The effects of pollution on deacidified paper. Restaurator 11: 179-207.

Daniels, V.D. (1996). The chemistry of paper conservation. Chem. Soc. Rev. 25: 179-186.

Davis, N. (2006). Tracing the evolution of preservation environments in archives, museums, and libraries. 20th Annual Preservation Conference: Beyond the Numbers: Specifying and Achieving an Efficient Preservation Environment. National Archives, Washington, D.C., March 16, 2006. http://www.archives.gov/preservation/ conferences/2006/presentations.html.

De Feber, M., Havermans, J. and Cornelissen, E. (1998). The positive effects of air purification in the Dutch State Archives part 1: Experimental set up and air quality. Restaurator 19: 212-222.

De Santis, F., Di Palo, V. and Allegrini, I. (1992). Determination of some atmospheric pollutants inside a museum: relationship with the concentration outside. Sci. Total Environ. 127: 211-223.

Dirksen, V. (1997). The degredation and conservation of leather. J. Conserv. Mus. Stud. 3: 6-10.

Founda, D. and Giannakopoulos, C. (2009). The exceptionally hot summer of 2007 in Athens, Greece-A typical summer in the future climate?. Global Planet Change 67: 227-236.

Founda, D. (2011). Evolution of the air temperature in Athens and evidence of climatic change: A review. $A d v$. Build. Energy Res. 5: 7-41.

Fourtziou, L., Liakakou, E., Stavroulas, I., Theodosi, C., Zarmpas, P., Psiloglou, B., Sciare, J., Maggos, T., Bairachtari, K., Bougiatioti, A., Gerasopoulos, E., SardaEstève, R., Bonnaire, N. and Mihalopoulos, N. (2017). Multi-tracer approach to characterize domestic wood burning in Athens (Greece) during wintertime. Atmos. Environ. 148: 89-101.

Gerasopoulos, E., Kokkalis, P., Amiridis, V., Liakakou, E., Perez, C., Haustein, K., Eleftheratos, K., Andreae, M.O., Andreae, T.W. and Zerefos, C.S. (2009). Dust specific extinction cross-sections over the Eastern Mediterranean using the BSC-DREAM model and sun photometer data: The case of urban environments. Ann. Geophys. 27. 2903-2912.

Gratsea, M., Liakakou, E., Mihalopoulos, N., Adamopoulos,
A., Tsilibari, E. and Gerasopoulos, E. (2017). The combined effect of reduced fossil fuel consumption and increasing biomass combustion on Athens' air quality, as inferred from long term CO measurements. Sci. Total Environ. 592: 115-123.

Grau-Bové, J. and Strlič, M. (2013). Fine particulate matter in indoor cultural heritage: A literature review. Herit. Sci. 1: 8 .

Grau-Bové, J., Budič, B., Kralj Cigić, I., Thickett, D., Signorello, S. and Strlič, M. (2016). The effect of particulate matter on paper degradation. Herit. Sci. 4: 2.

Gysels, K., Deutsch, F. and Van Grieken, R. (2002). Characterisation of particulate matter in the Royal Museum of Fine Arts, Antwerp, Belgium. Atmos. Environ. 36: 4103-4113

Gysels, K., Delalieux, F., Deutsch, F., Van Grieken, R., Camuffo, D., Bernardi, A., Sturaro, G., Busse, H.J. and Wieser, M. (2004). Indoor environment and conservation in the Royal Museum of Fine Arts, Antwerp, Belgium. $J$. Cult. Heritage 5: 221-230.

Hellenic Statistical Authority (2014). 2011 population and housing census. Hellenic Republic, Piraeus.

Henderson, J. (2013). Managing the Library and Archive Environment, Preservation Advisory Centre, London.

ISO 11799:2003. Information and documentation Document storage requirements for archive and library materials. ISO 2003, Geneva.

Johansson, A. and Lennholm, H. (2000). Influences of $\mathrm{SO}_{2}$ and $\mathrm{O}_{3}$ on the ageing of paper investigated by in situ diffuse reflectance FTIR and time-resolved trace gas analysis. Appl. Surf. Sci. 161: 163-169.

Johansson, A., Kolseth, P. and Lindqvist, O. (2000). Uptake of air pollutants by paper. Restaurator 21: 117-137.

Kite, M. and Thomson, R. (2006). Conservation of leather and related materials. Elsevier, Amsterdam.

Kliafa, M. (2013). In The Science of Preventive Conservation, Preservation and Collection Management. The Control of Particulate Pollutants in Indoor Exhibitions, the Case of Nationak Glyptothek, Karidis, C., Kouloubi, E. and Sakellariou, G.A. (Eds.), Time Heritage, p. 207.

Krupińska, B., Worobiec, A., Rotondo, G.G., Novaković, V., Kontozova, V., Ro, C.U., Van Grieken, R. and De Wael, K. (2010). Assessment of the air quality $\left(\mathrm{NO}_{2}, \mathrm{SO}_{2}\right.$, $\mathrm{O}_{3}$ and particulate matter) in the Plantin-Moretus Museum/Print Room in Antwerp, Belgium, in different seasons of the year. Microchem. J. 102: 49-53.

Krupińska, B., Van Grieken, R. and De Wael, K. (2013). Air quality monitoring in a museum for preventive conservation: Results of a three-year study in the PlantinMoretus Museum in Antwerp, Belgium. Microchem. J. 110: 350-360.

Kupczak, A., Bratasz, L., Krysciak-Czerwenka, J. and Kozłowski, R. (2018). Moisture sorption and diffusion in historical cellulose-basedmaterials. Cellulose 25: 28732884.

La Fontaine, R.H. (1979). Environmental Norms for Canadian Museums, Art Galleries, and Archives, CCI Technical Bulletin 5, Canadian Conservation Institute, Ottawa. 
Maskova, L., Smolik, J. and Vodicka, P. (2015). Characterisation of particulate matter in different types of archives. Atmos. Environ. 107: 217-224.

Menart, E., De Bruin, G. and Strlič, M. (2011). Doseresponse functions for historic paper. Polym. Degrad. Stab. 96: 2029-2039.

Morten, R.S. (2006). Indoor air pollution in museums: A review of prediction models and control strategies. Rev. Conserv. 7: 27-41.

Novakov, T., Menon, S., Kirchstetter, T. W., Koch, D. and Hansen, J.E. (2005). Aerosol organic carbon to black carbon ratios: Analysis of published data and implications for climate forcing, J. Geophys. Res. 110: D21205.

Panek, J., Fellers, C. and Haraldsson, T. (2004). Principles of evaluation for the creep of paperboard in constant and cyclic humidity. Nord. Pulp. Pap. Res. J. 19: 155-163.

Paraskevopoulou, D., Liakakou, E., Gerasopoulos, E., Theodosi, C. and Mihalopoulos, N. (2014). Long-term characterization of organic and elemental carbon in the $\mathrm{PM}_{2.5}$ fraction: The case of Athens, Greece. Atmos. Chem. Phys. 14: 13313-13325.

Paraskevopoulou, D., Liakakou, E., Gerasopoulos, E. and Mihalopoulos, N. (2015). Sources of atmospheric aerosol from long-term measurements (5 years) of chemical composition in Athens, Greece. Sci. Total Environ. 527528: $165-178$.

Pavlogeorgatos, G. (2003). Environmental parameters in museums. Build. Environ. 38: 1457-1462.

Sarantakos, G. (2013). In The Science of Preventive Conservation, Preservation and Collections Management. The Impact of Climate Change on Works of Art, Karidis, C., Kouloubi, E. and Sakellariou, G.A. (Eds.), Time Heritage, p. 357.

Sciare, J., Oikonomou, K., Cachier, H., Mihalopoulos, N., Andreae, M.O., Maenhaut, W. and Sarda-Esteve, R. (2005). Aerosol mass closure and reconstruction of the light scattering coefficient over the Eastern Mediterranean Sea during the MINOS campaign. Atmos. Chem. Phys. 5: 2253-2265.

Shahani, C.J., Hengemihle, F.H. and Weberg, N. (1989). The effect of variations in relative humidity on the accelerated aging of paper. In Historic Textile and Paper Materials II, Zeronian, S.H. and Needles, H.L. (Eds.), American Chemical Society, pp. 63-80.

Stavroulas, I., Bougiatioti, A., Paraskevopoulou, D., Grivas, G., Liakakou, E., Gerasopoulos, E. and Mihalopoulos, M. (2019). Sources and processes that control the submicron organic aerosol in an urban Mediterranean environment (Athens) using high temporal resolution chemical composition measurements. Atmos. Chem. Phys. 19: 901919.

Sterflinger, K. (2010). Fungi: Their role in deterioration of cultural heritage. Fungal Biol. Rev. 24: 47-55.

Tétreault, J. (2003). Airborne Pollutants in Museums, Galleries and Archives: Risk Assessment, Control Strategies and Preservation Management. Canadian Conservation Institute, Ottawa, Canada.

Theodosi, C., Tsagkaraki, M., Zarmpas, P., Grivas, G., Liakakou, E., Paraskevopoulou, D., Lianou, M., Gerasopoulos, E. and Mihalopoulos, N. (2018). Multiyear chemical composition of the fine-aerosol fraction in Athens, Greece, with emphasis on the contribution of residential heating in wintertime. Atmos. Chem. Phys. 18: 14371-14391.

Thomson, G. (1994). The Museum Environment (Conservation and Museology), 2nd ed., Butterworth-Heinemann, Oxford, U.K.

UNI 10586:1997. Documentation. Climatic Conditions to Document Storage of Graphic Documents and Characteristics of Lodging. Italian Standard.

Uring, P., Chabas, A., De Reyer, D., Gentaz, L., Triquet, S., Mirande-Bret, C. and Alfaro, S. (2018). The Bayeux embrodiery: A dust deposition assessment. Herit. Sci. 6: 23.

Vujcic, I., Masic, S., Medic, M., Putic, S. and Dramicanin, M.D. (2017). Gamma irradiation of leather gloves in terms of cultural heritage preservation. XXV Int. Conference "ECOLOGICAL TRUTH" ECO-IST'17, Vrnjacka Banja, Serbia, pp. 531-535.

Worobiec, A., Samek, L., Karaszkiewicz, P., KontozovaDeutsch, V., Stefaniak, E.A., Van Meel, K., Krata, A., Bencs, L. and Van Grieken, R. (2008). A seasonal study of atmospheric conditions influenced by the intensive tourist flow in the Royal Museum of Wavel Castle in Cracow, Poland. Microchem. J. 90: 99-106.

Xiu, G., Wu, X., Wang, L., Chen, Y., Yu, Y., Xu, F. and Wu, L. (2015). Characterization of particulate matter, ions and OC/EC in a museum in Shanghai, China. Aerosol Air Qual. Res. 15: 1240-1250.

Zorpas, A.A. and Skouroupatis, A. (2016). Indoor air quality evaluation of two museums in a subtropical climate conditions. Sustainable Cities Soc. 20: 52-60.

Received for review, July 24, 2019 Revised, November 9, 2019 Accepted, January 18, 2020 